\section{Pollen Morphology of Interspecific Hybrids of Brassica oleracea and $B$. campestris}

\author{
M.M. Hossain, H. Inden, and T. Asahira \\ Laboratory of Vegetable and Ornamental Horticulture, Faculty of \\ Agriculture, Kyoto University, Sakyoku, Kyoto 606, Japan
}

Additional index words. amphidiploid, scanning electron microscope

\begin{abstract}
Pollen morphology was examined in amphidiploid and amphidaploid interspecific hybrids between Brassica oleracea $\mathbf{L}$. and $B$. campestris $L$. Pollen of the amphidiploid interspecific hybrids between $B$. oleracea var. capitata and $B$. campestris var. pekinensis, and between B. campestris var. chinensis and B. oleracea var. capitata, were significantly longer and wider than those of their diploid parents, presumably due to the phenotypic expression of the hybrid genomes and ploidy effects. The exine ridges and pores of the amphidiploids were well-developed and significantly larger than those of their diploid parents, but they were poorly developed in the amphihaploids.
\end{abstract}

Successful production of resynthesized Brassica napus from its progenitors, $B$. oleracea and B. campestris, raised great interest in the breeding of Brassica (U, 1935). Thereafter, interspecific hybridization of these species frequently has been used to develop new types of vegetables, fodder crops, and oil seeds (Hossain et al., 1988). Many artificially synthesized $B$. napus recently have been released as cultivars (Namai et al., 1980). The fundamental problems of the interspecific hybrids, pollen sterility, and low seed production constitute a severe hindrance to their use for any agronomic potential (Hossain et al., 1987).

We studied the pollen morphology of $B$. campestris and B. oleracea, and their amphidiploid and amphihaploid interspecific

Received for publication 11 Oct. 1988. Critical review of this manuscript by L.L. Levenson is gratefully acknowledged. We thank Known-you Seed Co. Ltd., Taiwan, and Marutane Co., Japan, for providing seeds. The cost of publishing this paper was defrayed in part by the payment of page charges. Under postal regulations, this paper therefore must be hereby marked advertisement solely to indicate this fact. hybrids, in relation to pollen fertility. To our knowledge, there is no previous report on pollen morphology; i.e., pollen size, shape, and pore characteristics of the interspecific hybrids of these two taxa.

The species used were B. oleracea var. capitata CV. Yoshin (cabbage), B. oleracea var. alboglabra cv. Senyo shirobana (Chinese kale), B. campesti var. pekinensis cvs. Kaga and Kenshin (Chinese cabbage), and $B$. campestris var. chinensis CV. Honsaitai (Chinese vegetable). Seven plants from each of the parental species were used in the crosses. Interspecific hybrids in various cross combinations were developed through in vitro embryo and ovary culture (Hossain et al., 1987; Inden et al., 1987). The interspecific hybrids were sterile. Colchicine $0.3 \%$ (w/v) was applied at the six-to eight-leaf stage to double the chromosomes and restore fertility.

Mitotic chromosomes were counted in 10 metaphase cells in root tip meristematic tissue from the hybrids and the parental plants. The root tips were pretreated with $2 \mathrm{~mm} 8$ hydroxyquinoline and fixed in 3 absolute ethanol :1 glacial acetic acid. After fixation, the root tips were washed and treated with an enzyme solution containing $4 \%(\mathrm{w} / \mathrm{v})$ cellulase, $1 \%(\mathrm{w} / \mathrm{v})$ pectolyase, $7.5 \mathrm{~mm} \mathrm{KCl}$, and $7.5 \mathrm{~mm}$ EDTA, then stained with $2 \%$ (w/v) aceto-orcein for $20 \mathrm{~min}$ (Hossain et al., 1988). Pollen viability was estimated by counting 1000 pollen grains stained with acetocarmine.

All plants were held for 3 weeks under 16-hr daylength at $5 \mathrm{C}$ in a phytotron to induce flowering and then were grown in a glasshouse under natural daylight conditions at $20 \pm 5 \mathrm{C}$ for flowering.

Flowers were collected from glasshousegrown plants a few hours after anthesis. Anthers were removed and pollen grains of each plant were dusted on a polished aluminum disk stub covered with double-faced transparent tape. The sample on each stub was sputter-coated with 60:40 gold-palladium alloy $\approx 20 \mathrm{~nm}$ thick with an ion coater (Eiko, IB-3) and were examined with a scanning electron microscope (SEM) (Akashi, Alpha10) at a $35^{\circ}$ sample stub inclination. Three groups of 10 pollen grains per plant were examined at random. The data were analyzed by analysis of variance and the means were separated by Duncan's multiple range test at $P=0.05$,

Pollen length, width, and pore characteristics of the amphidiploids and amphihaploids interspecific hybrids are listed in Table 1. The size and shape of pollen grains varied between and among cultivars of the two species. Amphidiploid hybrids of 'Yoshin' $x$ 'Kaga' and 'Honsaitai' $x$ 'Yoshin' had significantly larger pollen grains than the others (Table 1, Fig. 1B). The pollen lengths and widths of the amphihaploid hybrids between 'Yoshin' $x$ 'Kenshin' and between 'Senyo shirobana' $x$ 'Kenshin' were significantly smaller than those of their diploid parents in the interspecific hybridization (Table 1, Fig. 1E). Maas (1977) reported that the sizes of pollen corresponded with ploidy levels in Fragaria. The pollen grains examined in each of the hybrids and the parents were monad and tricolpate, with the pore extending almost the full length of the grain. The pollen shape of the interspecific hybrids resembled that of the female parents.

The pollen exine varied greatly among the

Table 1. The pollen characteristics of the Brassica interspecific hvbrids (female parent $\times$ male parcrrt) and their parents.

\begin{tabular}{|c|c|c|c|c|c|c|c|c|c|c|c|c|}
\hline \multirow{3}{*}{$\begin{array}{l}\text { Cultivar/ } \\
\text { hybrid }\end{array}$} & \multirow[b]{3}{*}{ Species } & \multirow{3}{*}{$\begin{array}{l}\text { Ploidy } \\
\text { level }^{y}\end{array}$} & \multirow{3}{*}{$\begin{array}{c}\text { Chromosome } \\
\text { no. }\end{array}$} & \multirow[b]{3}{*}{ Shape } & \multicolumn{2}{|c|}{ Pollen } & \multirow{3}{*}{$\begin{array}{c}\text { Length : width } \\
\text { ratio }\end{array}$} & \multirow{2}{*}{\multicolumn{2}{|c|}{ Exine }} & \multicolumn{2}{|c|}{ Pore } & \multirow{3}{*}{$\begin{array}{c}\text { Pollen } \\
\text { fertility } \\
(\%)\end{array}$} \\
\hline & & & & & \multirow{2}{*}{$\begin{array}{c}\text { Length } \\
(\mu \mathrm{m})\end{array}$} & \multirow{2}{*}{$\begin{array}{l}\text { Width } \\
(\mu \mathrm{m})\end{array}$} & & & & \multirow{2}{*}{$\begin{array}{l}\text { Length } \\
(\mu \mathrm{m})\end{array}$} & \multirow{2}{*}{$\begin{array}{l}\text { Width } \\
(\mu \mathrm{m})\end{array}$} & \\
\hline & & & & & & & & Texturew & Shape & & & \\
\hline Yoshin & (B. oleracea) & $\mathrm{D}$ & 18 & NP & $34.4 \mathrm{f}$ & $19.1 \mathrm{de}$ & $1.80 \mathrm{c}$ & $\mathrm{RRi}$ & I & $1.08 \mathrm{~d}$ & $1.20 \mathrm{c}$ & 98.0 \\
\hline Senyo shirobana & (B. oleracea) & $\mathrm{D}$ & 18 & NP & $38.5 \mathrm{~d}$ & $18.8 \mathrm{de}$ & $2.05 \mathrm{~b}$ & $\mathrm{RRi}$ & I & $1.37 \mathrm{c}$ & $0.97 \mathrm{e}$ & 84.0 \\
\hline Kaga & (B. campestris) & $\mathrm{D}$ & 20 & $\mathrm{Ob}$ & $36.0 \mathrm{e}$ & $18.5 \mathrm{e}$ & $1.95 \mathrm{bc}$ & PRi & I & $1.57 \mathrm{~b}$ & $1.05 \mathrm{~d}$ & 98.5 \\
\hline Kenshin & (B. campestris) & D & 20 & $\mathrm{Ob}$ & $38.5 \mathrm{~d}$ & $20.3 \mathrm{c}$ & $1.90 \mathrm{c}$ & PRi & I & $0.81 \mathrm{e}$ & $0.82 \mathrm{f}$ & 97.0 \\
\hline Honsaitai & (B. campestris) & $\mathrm{D}$ & 20 & $\mathrm{BP}$ & $40.4 \mathrm{c}$ & $19.7 \mathrm{~cd}$ & $2.05 \mathrm{~b}$ & $\mathrm{PRi}$ & I & $1.56 \mathrm{~b}$ & $1.02 \mathrm{de}$ & 92.5 \\
\hline Yoshin $\times$ Kaga & & $\mathrm{Ad}$ & 38 & NP & $48.6 \mathrm{a}$ & $25.5 \mathrm{a}$ & $1.91 \mathrm{bc}$ & PRe & I & $1.80 \mathrm{a}$ & $1.48 \mathrm{a}$ & 75.0 \\
\hline Honsaitai $\times$ Yoshin & & Ad & 38 & $\mathrm{BP}$ & $44.0 \mathrm{~b}$ & $24.0 \mathrm{~b}$ & $1.83 \mathrm{c}$ & RRi & I & $1.60 \mathrm{~b}$ & $1.30 \mathrm{~b}$ & 81.5 \\
\hline Yoshin $x$ Kenshin & & $\mathrm{Ah}$ & 19 & NP & $35.4 \mathrm{e}$ & $15.9 \mathrm{f}$ & $2.23 \mathrm{a}$ & PRi & I & $1.00 \mathrm{~d}$ & $0.98 \mathrm{e}$ & 3.0 \\
\hline \multicolumn{13}{|l|}{ Senyo } \\
\hline shirobana $\times$ Kenshin & & $\mathrm{Ah}$ & 19 & NP & $20.6 \mathrm{~g}$ & $13.5 \mathrm{~g}$ & $1.53 \mathrm{~d}$ & PRe & $\mathrm{R}$ & $0.34 \mathrm{f}$ & $0.29 \mathrm{~g}$ & 11.5 \\
\hline
\end{tabular}

${ }^{2}$ Means separation within columns by Duncan's multiple range test, $P=0.05$.

${ }^{y} \mathrm{D}=$ Diploid, $\mathrm{Ad}=$ amphidiploid, $\mathrm{Ah}=$ amphihaploid,

${ }^{x} \mathrm{NP}=$ Narrowly prolate, $\mathrm{Ob}=$ oblong, $\mathrm{BP}=$ broadly prolate.

" $\mathrm{RRi}=$ Reticulately ridged, $\mathrm{PRi}=$ prominently ridged, $\mathrm{PRe}=$ prominently reticulated

'I = Irregular, R = round. 

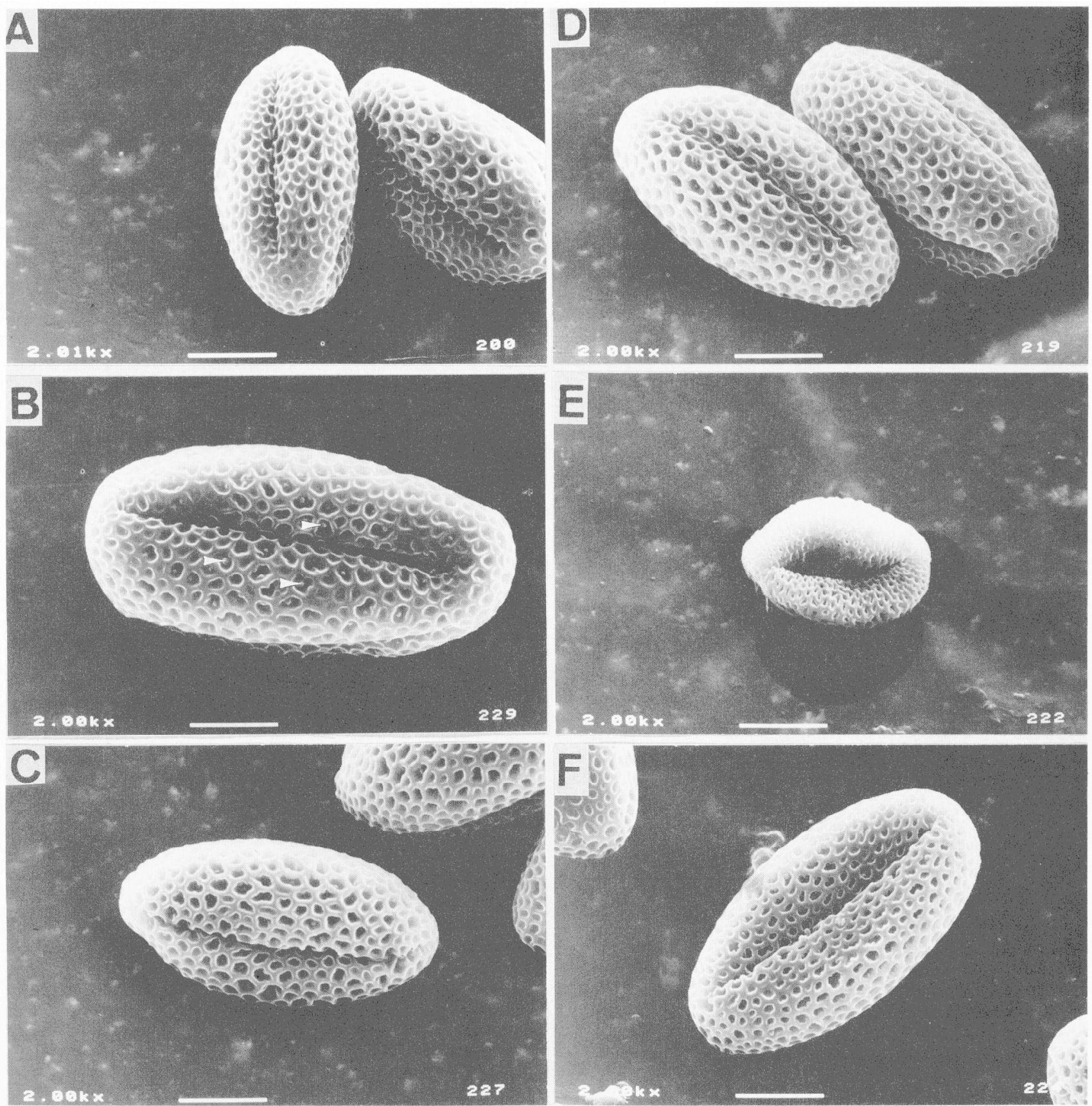

Fig. 1. Pollen morphology of amphidiploid and amphihaploid interspecific hybrids between Brassica oleracea and B. campestris (A-F). (A) A female parent 'Yoshin'; (B) an amphidiploid of 'Yoshin' × 'Kaga', arrowheads indicate minute protuberances in pores; (C) a male parent 'Kaga'; (D) a female parent 'Senyo shirobana'; (E) an amphihaploid of 'Senyo shirobana' x 'Kenshin'; (F) a male parent 'Kenshin'. Scale line equals $20 \mu \mathrm{m}$.

parents and the hybrids. The exine of 'Yoshin' and 'Senyo shirobana' (B. oleracea) were reticulately ridged, whereas 'Kenshin', 'Kaga', and 'Honsaitai' (B. campestris) had prominently ridged exine (Fig. $1 \mathrm{~A}, \mathrm{C}, \mathrm{D}$, and F). The interspecific hybrids of 'Yoshin' $x$ 'Kaga' had prominently ridged exine, while the hybrid between 'Honsaitai' $x$ 'Yoshin' was reticulately ridged. The exine character of the interspecific hybrids was closer to that of the pollen parents.

Significantly larger pollen pores were found in the two amphidiploid hybrids of 'Yoshin' $x$ 'Kaga' and 'Honsaitai' $x$ 'Yoshin' than in the other hybrids. An amphidiploid interspecific hybrid had distinct minute protuberances in pollen pores (Fig. 1B, arrows). When
B. campestris is used as the male parent in crosses to $B$. oleracea, the minute protuberances are distinct. This phenomenon is probably controlled by the pollen parent, or it may be the result of the phenotypic expression of the hybrid genomes (AACC).

Pollen fertility of the amphidiploid hybrids was significantly higher than amphihaploids (Table 1). Pollen of the amphihaploid hybrids was mostly sterile and poorly developed. The sterile and aborted pollen can also be identified through pollen morphology by light microscopy.

The present results reveal that pollen length, width, and pore characteristics can provide evidences for distinguishing the amphidiploid and amphihaploid interspecific hybrids.
These will be useful in practical breeding and backcrossing in interspecific hybridization in Brassica.

\section{Literature Cited}

Hossain, M. M., H. Inden, and T. Asahira. 1987. Production of interspecific hybrids in Brassica for the tropics: 11. Effects of media on the interspecific embryo and ovary development in vitro between B. campestris and B. oleracea. Jpn. Soc. Hort. Sci. Autumn Mtg. p. 230-231. (Abstr.)

Hossain, M. M., H. Inden, and T. Asahira. 1988. Intergeneric and interspecific hybrids through in vitro ovule culture in the Cruciferae. Plant Sci. 58:121-128.

Inden, H., M.M Hossain, and T. Asahira. 1987. Production of interspecific hybrids in Brassica 
for the tropics: I. Interspecific hybrids between $B$. campestris and B. oleracea through in vitro embryo culture. Jon. Soc. Hort. Sci. Autumn Mtg. p. 228-229. (Abstr.)

Maas, J.L. 1977. Pollen ultrastructure of strawberry and other small fruit crops. J. Amer. Sot.
Hort. Sci. 102:560-571

Namai, H., M. Sarashima, and T. Hosoda. 1980. Interspecific and intergeneric hybridization breeding in Japan, p. 191-201. In: S. Tsunoda, K. Hinata, and C. Gómez-Campo (eds.). Brassica crops and wild allies. Japan Scientific So- cietics Press, Tokyo.

U, N. 1935. Genome-analysis in Brassica with special reference to the experimcntal formation of B. napus and peculiar mode of fertilization. Jpn. J. Bet. 7:389-452.

\section{Survival of in Vitro-grown Apical Meristems of Pyrus Following Cryopreservation}

\author{
Barbara M. Reed \\ Department of Horticulture, Oregon State University and National Clonal \\ Germplasm Repository 33447 Peoria Road, Corvallis, OR 97333
}

Additional index words. conditioning, tissue culture, pear, cold-hardening, acclimation

Abstract. Apical meristems of four pears (Pyrus communis $L$. CV. Beurre Hardy, P. koehnei Schneider, $P$. cossonii Coss. and Dur., and a hybrid, P. dimorphophylla Makino $\times P$. fauriei Schneider) were tested for their ability to survive immersion in liquid nitrogen. Plantlets were grown in vitro at $25 \mathrm{C}$ or cold-hardened for 1 week at - 1C before cooling at rates of $0.1,0.3,0.5$, and $0.8 \mathrm{C} /$ rein to $-40 \mathrm{C}$, followed by plunging the vials into liquid nitrogen. Vials were thawed for $1 \mathrm{~min}$ at $40 \mathrm{C}$. A cryoprotectant mixture of polyethylene glycol, glucose, and dimethylsulfoxide (DMSO) was used. Regrowth of meristems ranged from $0 \%$ to $61 \%$ for plants grown at $25 \mathrm{C}$ and from $5 \%$ to $95 \%$ for cold-hardened plants. Cold-hardening significantly improved the recovery rates of all species tested. Survival rates increased as cooling rates decreased. Survival rates were not linked to the geographic origin of the species tested.

The development of methods to successfully store apical meristems in liquid $\mathrm{N}_{2}$ is needed to aid in the conservation of genetic resources. Long-term storage methods for Pyrus spp. are needed to provide a backup collection of the 26 species and numerous cultivars present at the National Clonal Germplasm Repository, Corvallis, Ore. Cryopreservation may be a useful method for long-term storage using a minimum of space and maintenance.

In freezing actively growing apical meristems of Pyrus species, variable survival over a range of conditions for dehydration could be expected. The rate of cooling and the prefreezing.. temperature must be taken into account (15). Relatively slow cooling rates may have the net effect of greater dehydration at a given temperature than faster rates, while the same level of dehydration would be reached at a lower temperature at faster cooling rates.

Enhanced survival has been found in callus of several species that were cold-hardened before cryopreservation $(8,10,12)$. One week of cold-hardening was found to in-

Received for publication 18 Nov. 1988. Contribution of the Oregon Agricultural Experiment Station in cooperation with the ARS/USDA Technical paper no. 8706 of the Ore. Agr. Expt. Sta. The cost of publishing this paper was defrayed in part by the payment of page charges. Under postal regulations, this paper therefore must be hereby marked advertisement solely to indicate this fact. crease the survival of cryopreserved apical meristems from tissue-cultured Rubus plants (6). Dormant apple buds survived best in liquid $\mathrm{N}_{2}$ when the tissue had $\leq 20 \%$ liquid water at the precooking temperature and the cell solute concentration had increased from about $2 \mathrm{mmol}$ to $5 \mathrm{mmol}$ with dehydration, leading to higher survival rates (14).

Field-grown pear species and cultivars vary in hardiness to freezing damage of cambial cells from temperatures of $-16 \mathrm{C}$ to $-40 \mathrm{C}$ (5). Pyrus communis cultivars alone vary in hardiness from -20 to $-35 \mathrm{C}$ (J.M. Montano, unpublished results). Other species ex-
${ }^{2} \mathrm{G}$ values calculated as in Sokal and Rohlf (11).

*** Significant at $P<0.001$. hibit somewhat greater or lesser hardiness that often is well-correlated with the geographic origin of the plant (7). Sakai (9) found that, in the cryopreservation of woody twigs, the greater the hardiness, the higher the precooking temperature that is required for survival. Cryopreservation of Pyrus spp. has been limited to the cooling of dormant buds during midwinter $(4,8)$ and to protoplasts and suspension-cultured cells $(1,16)$.

Both cold-hardening and dehydration due to pretreatment and cooling rate play important roles in conditioning meristems to survive immersion in liquid $\mathrm{N}_{2}(13,14)$. This study compares the survival of apices of four species of the genus Pyrus that were frozen at four rates following growth under coldhardening or growth room conditions.

Tissue culture conditions. Tissue-cultured plants of $P$. communis, $P$. koehnei, and $P$. cossonii and of a hybrid, $P$. dimorphophylla Makino $\times P$. fauriei, were grown on the medium of Cheng (2) with benzyladenine at 2 mg.liter ${ }^{-1}$ and $0.6 \%$ agar at $\mathrm{pH}$ 5.2. Growth conditions included a 16-hr photoperiod at 25C. Cold-hardening of in vitro plants involved $22 \mathrm{C}$ days $(8 \mathrm{hr}$ ) and $-1 \mathrm{C}$ nights (16 hr) for 1 week before excision of meristems (6). Dissected meristems $(0.8 \mathrm{~mm})$ of both treatments were grown for $48 \mathrm{hr}$ on medium with $0.8 \%$ agar and 5\% DMSO added. Meristems were grown under the same conditions as the parent plants.

Addition of cryoprotectant. Following coldhardening, meristems were transferred to 0.25 $\mathrm{ml}$ of liquid medium in 1.2-ml plastic cryotubes on ice. The cryoprotectant PGD (3), a mixture of $10 \%$ each of polyethylene glycol $\left(M_{r} 8000\right)$, glucose, and DMSO in water, was added dropwise up to $1.2 \mathrm{ml}$ over 30

Table 1. Influence of cold-hardening or growth at $25 \mathrm{C}$ (non-hardened) on the survival of meristems of Pyrus spp. after cryopreservation in liquid $\mathrm{N}_{2}$ (all cooling rates combined).

\begin{tabular}{|c|c|c|c|c|c|c|}
\hline \multirow[b]{3}{*}{ Species } & \multicolumn{6}{|c|}{ No. meristems tested } \\
\hline & \multicolumn{3}{|c|}{ Cold-hardened } & \multicolumn{3}{|c|}{ Non-hardened } \\
\hline & Living & Dead & Total & Living & Dead & Total \\
\hline P. communis & 73 & 57 & 130 & 9 & 99 & 108 \\
\hline$P$. hybrid & 35 & 107 & 142 & 6 & 113 & 119 \\
\hline P. koehnei & 31 & 110 & 141 & 1 & 114 & 115 \\
\hline P. cossonii & 42 & 108 & 150 & 7 & 85 & 92 \\
\hline Total & 181 & 382 & 563 & 23 & 411 & 434 \\
\hline & \multicolumn{3}{|c|}{$\mathrm{df}$} & \multicolumn{2}{|c|}{$\mathrm{G}^{\mathrm{z}}$} & \\
\hline P. communis & \multicolumn{2}{|c|}{1} & & \multicolumn{2}{|c|}{$66.34 * * *$} & \\
\hline$P$. hybrid & \multicolumn{2}{|c|}{1} & & \multicolumn{2}{|c|}{$20.83^{* * *}$} & \\
\hline P. kochnei & \multicolumn{2}{|c|}{1} & & \multicolumn{2}{|c|}{$32.89^{* * *}$} & \\
\hline P. cossonii & \multicolumn{2}{|c|}{1} & & \multicolumn{2}{|c|}{$16.45^{* * *}$} & \\
\hline Species totals & \multirow{2}{*}{\multicolumn{2}{|c|}{$\begin{array}{l}3 \\
7\end{array}$}} & & \multicolumn{2}{|c|}{$40.15^{* * *}$} & \\
\hline Total & & & & \multicolumn{2}{|c|}{$176.67^{* * *}$} & \\
\hline
\end{tabular}

